\title{
How it adds up: dual reflections on the online engagement of one cohort of accounting students
}

\author{
Vicky Collins \\ University of Reading, UK \\ Sue Blackett \\ University of Reading, UK
}

Keywords: International students; accounting and finance; online learning; English for Academic Purposes; Covid-19.

\section{The challenge}

In September 2020 module preparation began with a plethora of TEL (Technology Enhanced Learning) support and a bankable level of expertise in online teaching garnered over the summer. For the autumn term, the university pursued a blended learning approach, combining face-to-face interactive sessions and online core materials. In the spring term teaching was moved online following government restrictions.

As lecturers from different disciplines, we present insights into our roles of teaching the same cohort of 26 MSc Accounting and Finance students from autumn 2020 through to spring 2021. Approximately $80 \%$ pursued their studies remotely and the majority were L2 English speakers from non-alphabetic language systems. A proportion of students each year complete pre-sessional English Language programmes to meet language requirements or hold an undergraduate degree from a UK university. Levels of language proficiency, adaptation to new content, and a new out-of-class approach to learning had an observable negative effect on participation compared to pre- Covid-19 teaching as evidenced by statistical data on user activity within the VLE (Virtual Learning Environment), and preparedness for synchronous activity. This multi-disciplinary account reflects on the emerging obstacles to student engagement in the online environment, and adjustments made to respond to these. 


\section{The disciplinary context: Accounting and Finance}

Face-to-face accounting information systems classes are dynamic with the focus being on students assimilating new information through the active learning technique of guided discovery (Fry et al., 2014) and sharing ideas through peer learning (Crouch and Mazur, 2001). This creates micro-communities of learners that through participation, share a common experience resulting in high levels of engagement.

\section{The disciplinary context: English for Academic Purposes}

Rather than following the lecture/seminar model, English Specific for Academic Purposes (ESAP) involves collaboratively unpacking spoken or written texts in groups of 16 maximum. Traditional classes usually focus on both productive and receptive interactive language tasks with considerable student-to-student interaction and tutor facilitation. 'Pandemic pedagogy', with its emphasis on a flipped classroom - the virtues of which have been extolled in language learning (Mehring and Leis, 2018) - offered a new approach to incorporating these skills.

Students were expected to engage firstly with one hour of asynchronous material and consolidate understanding in the live lesson. However, three weeks in, it was clear that student participation in pre-class activities was not fulfilling expectations and rather than feeling 'flippin' marvellous' (Fry, 2020), we felt more flipped out. Two issues emerged: it was not ideal for learners to encounter material 'cold', i.e., without the scaffolding a tutorled approach affords. Secondly, the time required to complete the materials was invisible to students as it was not represented on the timetable. This was particularly problematic for the ESAP non-credit bearing module as it was a lower priority for students.

Despite well-signposted instructions and scaffolded online resources, review of VLE module analytics further revealed that few students completed the asynchronous resources. The result was that the cohort was underprepared for the live sessions. This was evidenced by student cameras being switched off, and a general reluctance to speak or use the chat function to discuss lecture content. The absence of visual and verbal clues from the students made it impossible to deliver timely feedback and adjust module delivery and content to better cater to student needs. 


\section{The response}

For the ESAP module, the pre-lesson element was removed and students instead worked through tasks collaboratively with the tutor at first sight in the live class. Extension tasks were set from this, therefore the live workshop acted as a primer for further asynchronous activities. Student participation improved marginally but most importantly nobody lost face by admitting incompletion of pre-class work and this served well to improve tutor-student relations.

Online drop-in office hours for students to voluntarily attend and discuss issues with core discipline-specific materials were also established. Alas, for every week of term, the module convenor was alone in the virtual meeting room perhaps because students were embarrassed or felt they were imposing on lecturer time (Cronin, 1991, cited Guerrero and Rod, 2013). Becoming ever more nervous, the response was to increase the frequency of communications via VLE announcements and cohort-wide emails. Yielding little engagement, the student representative was approached as a conduit to communicate with his peers. A positive result is that a preferred channel of communication was found, and whilst not ideal, the student representative was able to confirm that his peers had received, and were aware, of key information.

\section{Recommendations}

Students' overall engagement with the new online culture can be observed through Anderson's (1994) model of cross-cultural adaptation. A few of the 26 students were 'participators'. They were effective in asynchronous tasks and showed direct inquiry with us in live online lessons. Some students demonstrated that they were 'adjusters'. They tried to understand the new situation but were still actively coping throughout both terms. Most students displayed 'time-server' behaviours by working at a low capacity with minimal participation and exhibiting poor productivity in their work (Anderson, 1994). With in-person delivery, degrees of engagement are also displayed; however, our takeaway is that remote learning coupled with studying outside the UK magnified this minimal participation and poor productivity. The statistical data showing student use of online resources (Figure 1) broadly reflects these findings. 
Figure 1. Extract from VLE showing frequency of student access to accounting module resources.

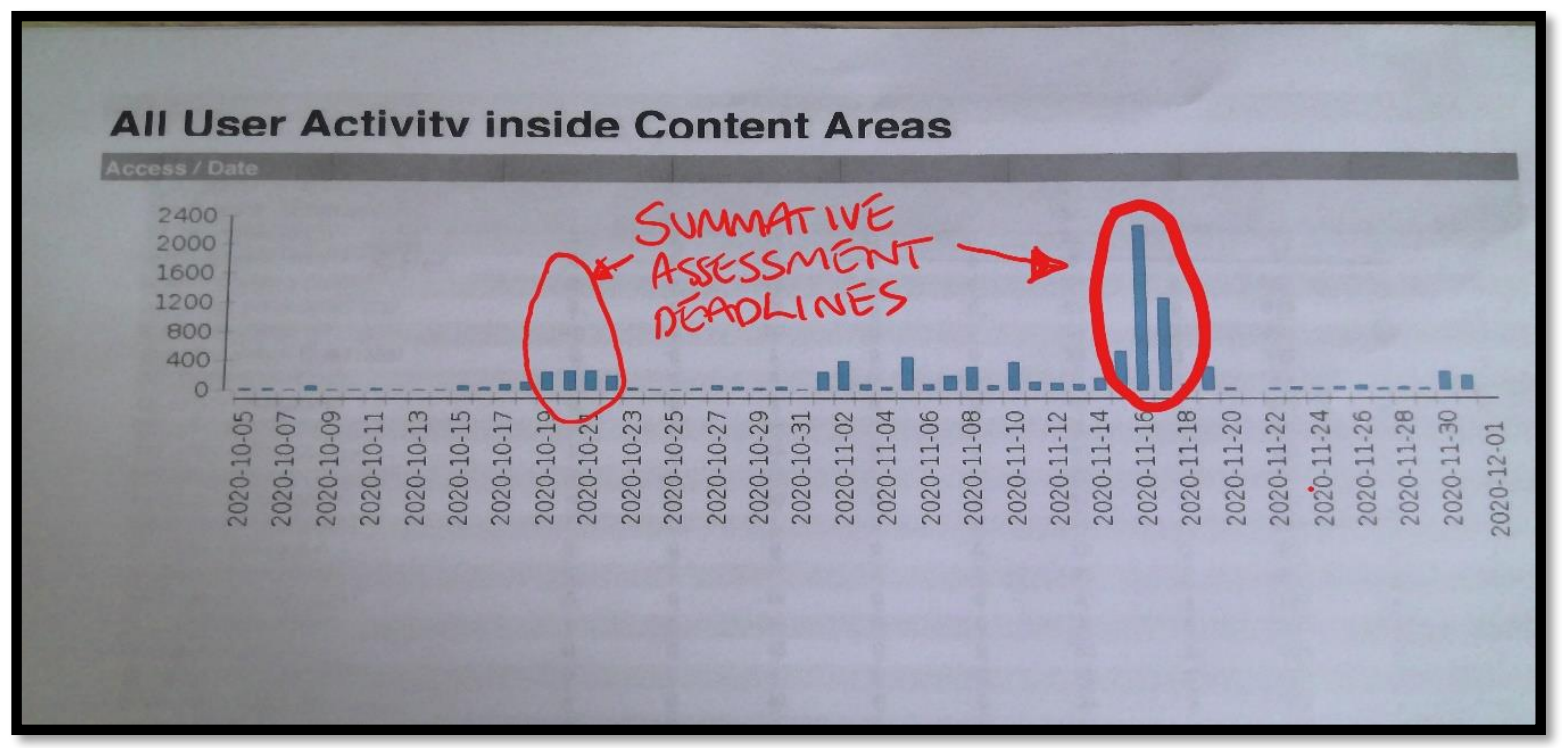

Students were more active in accessing resources before the summative assessments deadlines in February and April, supporting our 'time-server' behaviours observations. We assert that this behaviour contributed to lower coursework results for the module compared to previous years (Figure 2).

Figure 2. Comparison of Accounting module results 2017/18-2021.

\begin{tabular}{|c|c|c|c|c|c|}
\hline & \multicolumn{5}{|c|}{ Assessment Format } \\
\hline & In-class Test 1 & $10 \%$ & $10 \%$ & $20 \%$ & \\
\hline & In-class Test 2 & $20 \%$ & & & \\
\hline & Coursework* & $70 \%$ & $70 \%$ & $60 \%$ & $100 \%$ \\
\hline & Presentation & & $20 \%$ & $20 \%$ & \\
\hline & Delivery & Blended & $F 2 F$ & $F 2 F$ & $F 2 F$ \\
\hline & & $2020-21$ & 2019-20 & 2018-19 & 2017-18 \\
\hline Average coursework marks & & $48.32 \%$ & $51.44 \%$ & $57.81 \%$ & $58.66 \%$ \\
\hline Coursework* was reduced & from 6,000 wor & in $2017 / 18$ & 3,000 wo & from 2018, & onwards \\
\hline
\end{tabular}

As digital learning becomes part of what a university does, institutions may consider additional support for inducting students into their instructional approaches. A gradual implementation of the flipped classroom would be less daunting for learners (Lo and Hew, 2017). Monitoring engagement for different provisions and over a longer period is also 
recommended. Finally, greater timetabled visibility of asynchronous content could enhance participation by assisting students with time management.

\section{References}

Anderson, L. (1994) 'A new look at an old construct: cross-cultural adaptation', International Journal of Intercultural Relations, 18(3), pp.293-328. https://doi.org/10.1016/0147-1767(94)90035-3.

Crouch, C. and Mazur, E. (2001) 'Peer instruction: ten years of experience and results', American Journal of Physics, 69(9), pp.970-977. https://doi.org/10.1119/1.1374249.

Fry, S. (2020) 'Flippin' marvellous!', Education Technology, 9 October. Available at https://edtechnology.co.uk/features/update-flipped-learning-et/ (Accessed: 30 April 2021)

Fry, H., Ketteridge, S., Marshall, S. and Ketteridge, S. (2014) A handbook for teaching and learning in higher education: enhancing academic practice. London: Routledge.

Guerrero, M. and Rod, A. B. (2013) 'Engaging in office hours: a study of student-faculty interaction and academic performance', Journal of Political Science Education, 9(4), pp.403-416. https://doi.org/10.1080/15512169.2013.835554.

Lo, C. K. and Hew, K. F. (2017) 'A critical review of flipped classroom challenges in K-12 education: possible solutions and recommendations for future research', Research and practice in Technology Enhanced Learning, 12(4), pp.1-22. https://doi.org/10.1186/s41039-016-0044-2.

Mehring, J. and Leis, A. (2018) Innovations in flipping the language classroom: theories and practices. $1^{\text {st }}$ edn. Singapore: Springer Singapore. 


\section{Author details}

Vicky Collins is an EAP Lecturer at the International Study and Language Institute (ISLI), University of Reading. She works with a range of different student cohorts in her roles as Academic Language and Literacy Liaison for the Business School, Pre-Sessional English Language Coordinator, and on global graduate modules for Study Abroad/Erasmus programmes. Her professional interests include curriculum design and an exploration of genres of academic writing in the Business school.

Sue Blackett is a lecturer in accounting at Henley Business School, University of Reading. She works with predominantly postgraduate students and is the Programme Director for the BSc Accounting \& Finance programme. She leads a variety of accounting subjects such as Accounting Information Systems, Management Accounting: Theory \& Practice and Business in Practice: Accounting for Managers. Professional interests include widening accessibility and curriculum and assessment design in accounting. 